\title{
Forced vital capacity (FVC), peaked expiratory flow rate (PEFR), are additional parameters in the assessment of the reversibility test.
}

\author{
Mustafa N. Abd Ali * \\ Ahmed H. Jasim** \\ Abdulrasool N. Nassr*** \\ Monqith A. Kadhim****
}

\author{
CABM, FICMS \\ FICMS \\ CABM, FICMS \\ FICMS
}

JFac Med Baghdad 2018; Vol.60, No.1 Received Nov. 2017 Accepted Mar. 2018

Background: Spirometry is important test performed in patients expect to have air way obstruction, assessment of intense reaction to inhalers (the trial of reversibility of air way blockade) is a normally utilized technique in clinical and academic studies. The consequences of this test are utilized to take choices on treatment, consideration, exclusion from diagnosis and other research thinks about, and for analytic marking [asthma versus chronic obstructive air way disease (COPD)]. Usually, the (FEV1) or (FVC) standards before and after giving of the bronchodilator are compared and the adjustment is processed to distinguish variations from the norm in lung volumes and air flow.

Objective: The aim of this study was to investigate the effectiveness of FVC and PEFR as further constraints to evaluate bronchodilator reaction in asthmatic peoples with severe or moderate airflow blockade.

Patients and methods: This study is cross sectional study performed in Baghdad teaching hospital where one hundred patient were enrolled in this study patients were detected with asthma and confirm airway blockade according to (GINA) guide lines. The pulmonary function for all members were investigated with a convenient spirometer (spiro-lab3 Spirometer) as stated by those measures from claiming American thoracic particular social order, The mean and standard deviation results of predicted $\%$ values pulmonary function test were also used for comparisons were measured by $\mathrm{t}$ test. A p-value of $\leq 0.05$ considered to be significant statistically.

Results: The post bronchodilator (post -BD) results of FVC, PEFR are greater than prebronchodilator where are statistically significant $\mathrm{P}$ value $=0.00$. the amount of the changes of FVC post (BD) was more than $400 \mathrm{ml}$ from pre (BD) and the amount of the changes of PEFR post (BD) more than $1000 \mathrm{ml}$ from the pre $(\mathrm{BD})$ both were $\mathrm{p}$ value $=0.00$.

Conclusion: The asthmatic patients with moderate and severe airway obstruction, we observed that FVC and PEFR is a valuable important limit to FEV1 to evaluate reversibility reaction

Key word: forced vital capacity(FVC), peaked expiratory flow rate (PEFR), spirometry and forced expiratory volume in $1^{\text {st }}$ second (FEV1).

\section{Introduction:}

Spirometry is the important test performed to distinguish variations from the norm in lung volumes and air flow [1]. The most generally utilized pulmonary function test in clinical practice is spirometry. In patients found to have air way obstruction, assessment of response to inhalers (the trial of reversibility of air way blockade) is a normally utilized technique in clinical and inquire about examinations. The consequences of this test are utilized to take choices on treatment, consideration, aim exclusion from diagnosis and other research thinks about, and for analytic marking

\footnotetext{
*Dept. of Medicine, College of Medicine, University of Medicine.

** Dept. of Medicine, College of Medicine, University of Babylon.

*** Baghdad Teaching Hospital-Medical City. rasoolalmoosawi@yahoo.com

**** Babylon Health Center. Imam Al-Sadiq

Teaching
}

[asthma versus chronic obstructive air way disease (COPD)]. Usually, the $\left(\mathrm{FEV}_{1}\right)$ or $(\mathrm{FVC})$ standards before and after giving of the bronchodilator are compared and the adjustment is processed. While there is no evidence accord on what establishes bronchodilator or a critical intense reaction to a nebulizer, the frequently utilized criteria for a bronchodilator reaction (BDR) are those prescribed by (ATS), i.e. an increase of $12 \%$ and $200 \mathrm{ml}$ in FEV1 or FVC over the base line values[2].It is well known that airway obstruction in asthma usually shows a good response to bronchodilators while that in COPD is generally poor. The above cut-off is therefore often used to diagnose these diseases. Generations of students have been taught that asthma and COPD can be differentiated by the test of BDR, i.e., an increase of $12 \%$ and $0.2 \mathrm{~L}$ in $\mathrm{FEV}_{1}$ or FVC over the starting point results or more than this being diagnostic of the former and a lesser response diagnosing COPD. In any case, it has been called attention to in writing that "reversibility 
versus irreversibility" isn't a fitting methodology in making a distinctions between the two diseases, as "irreversible" exclude the diagnosis of asthma and numerous patients with COPD have a significant reversibility [3,4] In COPD, an special FVC response (post-bronchodilator rise only in FVC) was the major response, occurred in an important number of patients, whereas a selected $\mathrm{FEV}_{1}$ response (postbronchodilator increase only in $\mathrm{FEV}_{1}$ ) was unusual. Asthmatics had a tendency to react with an increase in both FVC and FEV1.[5] more recently, we have demonstrated that the trial of intense reversibility reaction has constrained indicative encouragement in isolating asthma and COPD. Positive perceptive estimations of $81 \%$ of sample in this examination with the ATS rules suggested that one can make sure of a determination of asthma to this degree when the BDR surpasses this limit and the negative prescient estimations of $64 \%$ showed the likelihood of an analysis of COPD when the reaction was not as much as the edge. Consequently, this cut-off left a considerable degree for misdiagnosis. [6] The current updates of the strategies on asthma and COPD have also highlighted that the identification of these illnesses is mainly clinical and the outcomes of spirometry necessity to be deduced in the clinical background.[7-9] Bronchodilators are the treatment of decision in COPD. It is the experience of each doctor watching over such patients that these medications create a variable however noteworthy change in an extent of patients after some time. This change might be clear in an enhanced FVC or inspiratory capacity(IC) (reflecting diminished air trapping and hyperinflation) and in addition in understanding focused results, for example, dyspnea, personal satisfaction, and exercise tolerance. 10] The long-term reaction to bronchodilators can't be anticipated by the intense BDR amid the trial of reversibility. As saw in a current report, patients with a BDR don't contrast in mortality, hospitalization, or worsening background from "irreversible" patients. In this way, bronchodilator reversibility status does not recognize clinically important results, making it a temperamental phenotype.[11] positive bronchodilator reaction is set up in light of an expansion $\geq 12 \%$ and $0.2 \mathrm{~L}$ in (FVC) as well as (FEV1) contrasted and reference measuresafter giving of nebulizers [12].In patients with (COPD), in whom the reversibilitytest is often not reversible, (VC) and (IC) variety are utilized as correlative instruments keeping in mind the end goal to assess bronchodilator reaction [13]chronic air way obstruction participantshad irreversible bronchial limitation ,also be noticed insevere ormoderate asthma; appraised the helpfulness of VC to evaluate bronchodilator reaction amongasthmatic patients [14].

\section{Aim of the study}

The idea of this study was to investigate the effectiveness of FVC and PEFR as furtherlimitations to evaluate bronchodilator reaction in asthmatic peoples with severe or moderate airflow blockade.

Patients and materials

This study is cross sectional performed in Baghdad teaching hospital where one hundred patients were enrolled in this study patients were detected with asthma and insistent airway blockade according to (GINA) measures.

Exclusion conditions

Uncontrolled hypertension

Heart failure

Pregnancy

Active smoking

Morbid obesity

Chest wall deformity

Fibrosis on chest $\mathrm{x}$ ray

Neuromuscular disease

Patientsuse short acting inhalers, long acting inhalers or theophylline by mouth $8 \mathrm{~h}, 12 \mathrm{~h}$ or $48 \mathrm{~h}$ on sequence before the spirometry.

Asthma exacerbation in last week

The reversibility procedure was done with salbutamol/400 $\mu \mathrm{g}$ nebulizer specialist observation, Bronchodilator response was considered increment in FEV1 $\geq 12 \%$ or 0.2 Lfrom starting point result.

The pulmonary function for all members were investigated with a convenient spirometer (spirolab3 Spirometer) as stated by those measures from claiming American thoracic particular social order

\section{Statistical analyses:}

Were constructed with an individual check by means of thatmeasurable one bundle for social Sciences (SPSS) version 22 project to Windows. Themean and standard deviation results of predicted $\%$ values pulmonary function test were also used for comparisons were measured by t-test. A p-value of $\leq 0.05$ considered to be important statically.

\section{Results:}

During period of the examination 100 patients were enrolled to this study diagnosed as moderate to severe asthma the demographic features presented on table 1 and Fig 1

Table 1: Demographic features( sex) in moderate and sever asthmatics

\begin{tabular}{ccccc}
\hline Sex & Frequency & Percent & Valid Percent & $\begin{array}{l}\text { Pumulative } \\
\text { Percent }\end{array}$ \\
\hline $\begin{array}{l}\text { Mm } \\
\text { male }\end{array}$ & 46 & 46.0 & 46.0 & 46.0 \\
\hline $\begin{array}{l}\text { female } \\
\text { Total }\end{array}$ & 100 & 54.0 & 54.0 & 100.0 \\
\hline
\end{tabular}




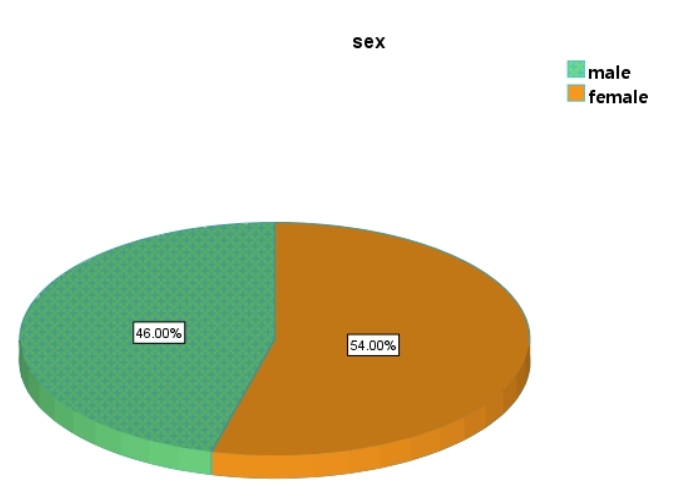

Fig 1: The clinical data (mean and $\mathrm{St}$ deviation) are presented on table 2

Table 2:ExpressiveMeasurements

\begin{tabular}{llllll}
\hline & $\mathrm{N}$ & Minimum & Maximum Mean & Std. Deviation \\
\hline Age & 100 & 9.00 & 81.00 & 44.3800 & 18.45649 \\
\hline weight & 100 & 21.00 & 133.00 & 79.9400 & 23.05760 \\
\hline Height & 100 & 125.00 & 190.00 & 162.0800 & 12.07191 \\
\hline Valid N & 100 & & & & \\
\hline
\end{tabular}

The observed results for patients with severe and moderate blockadepre and post the nebulizer (BD), (mean, Std. Deviation and P value) test are depicted in Table 3, 4. The post bronchodilator results of FVC, PEFR are larger than pre bronchodilator where are statistically significant $\mathrm{P}$ value $=0.00$. the amount of the changes of FVC post (BD) was more than $400 \mathrm{ml}$ from pre (BD) and the amount of the changes of PEFR post (BD) more than $1000 \mathrm{ml}$ from the pre $(B D)$ both were $p$ value $=0.00$.

Table 3: Mean and Std. Deviation(Pre) and (Post) the nebulizer (BD)

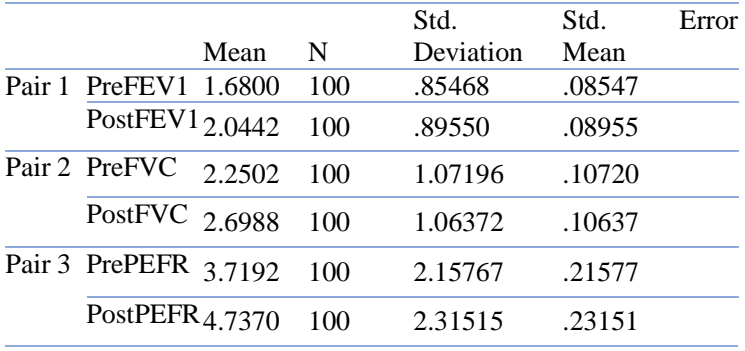

Table 4: The relationship (Pre) and (Post) the nebulizer (BD) Tpaired test

\begin{tabular}{llllll}
\hline & & \multicolumn{2}{c}{ N } & Correlation & P value. \\
\hline Pair 1 & $\begin{array}{l}\text { Pre FEV1 } \\
\text { FEV1 }\end{array}$ & Post $_{100}$ & .980 & .000 \\
\hline Pair 2 & \multicolumn{2}{l}{ Pre FVC \& Post FVC } & 100 & .983 & .000 \\
\hline Pair 3 & $\begin{array}{l}\text { Pre PEFR\& } \\
\text { PEFR }\end{array}$ & Post $_{100}$ & .965 & .000 \\
\hline
\end{tabular}

Discussion:
In this study examine the participants with asthma patients with moderate and severe obstruction; we watched that FVC and PEFR is a valuable important constraint to FEV1 to evaluate reversibility reaction. Bronchial hyper responsiveness participants were allocated to asevereor moderate air way limitation in view of FEV1 examination. Paré et al. had depicted 2 examples of reaction to nebulizer treatment: dominating increment in FVC (volume increment) or FEV1 (flow increment). Capacity responders displayed bring down PEFR and more prominent level of air duping [15]. Previous study by Newton et al., found same result also [16]. Sorkness et al., seeing 287 participants with established however severe bronchial hyper responsiveness, exhibited this gathering displayed conspicuous air duping rather than people with mild to moderate bronchial hyper responsiveness [14]. Our patients with extreme wind stream impediment had both more prominent $\mathrm{FVC}$ reaction in the gathering and more noteworthy air catching. The post-BD reaction of $\mathrm{VC}$ was very much associated with the variety in RV/TLC proportion in the extreme obstruction group. Previous study, O'Donnell et al. examined 84 participants with COPD without reaction in FEV1 and revealed a direct relationship between variety in FVC and FRC and IC after utilization of nebulizer [17]. Moreover, Newton et al. shown that lung capacity change was not related of changes in FEV1 in patients with severe and moderate hyperinflation [18]. Teeter et al. found that hyper responsiveness air way signs were unwell related with FEV1 before and after nebulizer [19].

\section{Conclusions:}

The present discoveries propose that FVC and PEFR might be helpful in expansion to FEV1 to distinguish reversibility reaction in hyper responsiveness airway patients with severe air flow limitation .

\section{Authors' contributions}

Mustafa Nema Abd Ali - Data collection

Ahmed Hussein Jasim - Statistics

Abdul rasool Noori Nassr - Revision and Advice Monqith Abdul Mohsin Kadhim- Writing

\section{References}

1. National Institute for Health and Clinical Excellence. Management of chronic obstructive pulmonary disease in adults in primary and secondary care (partial update). 2010. www.nice.org.uk/CG101

2. American Thoracic Society. Medical section of the American Lung Association. Lung function testing: Selection of reference values and interpretative strategies. Am Rev Respir Dis. 1991;144:1202-18

3. Meslier N, Racineux JL, Six P, Lockhart A. Diagnostic value of reversibility of chronic airway obstruction to separate asthma from chronic 
bronchitis: A statistical approach. Eur Respir J. 1989;2:497-505. [PubMed]

4. Dow L. Asthma versus chronic obstructive pulmonary disease exploring why 'reversibility versus irreversibility' is no longer an appropriate approach. Clin Exp Allergy. 1999;29:739-43. [PubMed]

5. Chhabra SK, Bhatnagar S. Comparison of bronchodilator responsiveness in asthma and chronic obstructive pulmonary disease. Indian $J$ Chest Dis Allied Sci. 2002;44:91-7. [PubMed]

6. Chhabra SK. Acute bronchodilator response has limited value in differentiating bronchial asthma from COPD. J Asthma. 2005;42:367-72. [PubMed] 7. Chronic obstructive pulmonary disease: Management of chronic obstructive pulmonary disease in adults in primary and secondary care (partial update) London: National Clinical Guideline Centre; 2010. [Last accessed on 2012 Nov 02]. National Institute for Health and Clinical Excellence. Available from: http://www.nice.org.uk/CG101.

8. Global Initiative for Chronic Obstructive Lung Disease (GOLD) Global strategy for the diagnosis, management and prevention of chronic obstructive pulmonary disease: Revised update 2011. Global Initiative for Chronic Obstructive Lung Disease. [Last accessed on 2012 Nov 02]. Available from: http://www.goldcopd.com.

9. Global Initiative for Asthma. Global strategy for asthma management and prevention. Revised 2011. [Last accessed on 2012 Nov 02]. Available from: http://www.ginaasthma.com.

10. Calverley PM, Burge PS, Spencer S, Anderson $J A$, Jones PW. Bronchodilator reversibility testing in chronic obstructive pulmonary disease. Thorax. 2003;58:659-64. [PMC free article] [PubMed] 11. Albert P, Agusti A, Edwards L, Tal-Singer R, Yates J, Bakke $P$, et al. Bronchodilator responsiveness as a phenotypic characteristic of established chronic obstructive pulmonary disease. Thorax. 2012;67:701-8. [PubMed]
12. Pellegrino R, Viegi G, Brusasco RO, Crapo R, Burgos F, Casaburi R, Coates A, Van Der Grinten $C P M$, Gustafsson $P$, Hankinson J, Jensen $R$, Johnson DC, Macintyre N, Mckay R, Miller MR, Navajas D, Pederson OFWangerJ: Interpretative strategies for lung function tests. Eur Respir J 2005, 26:948-68.

13. O'Donnell DE, Lam M, Webb KA: Measurement of symptoms, lung hyperinflation, and endurance during exercise in chronic obstructive pulmonary disease. Am J Respir Crit Care Med 1998, 158:1557-1565.

14. Sorkness RL, Bleecker ER, Busse WW, Calhoun WJ, Castro M, Chung KF, Curran-Everett D, Erzurun SC, Gaston BM, Israel E, Jarjour NN, Moore WC, Peters SP, Teague WG, Wenzel SE: Lung function in adults with stable but severe asthma: air trapping and incomplete reversal of obstruction with bronchodilation. J Appl Physiol 2008, 104:394-403.

15. Paré PD, Lawson LM, Brooks LA: Patterns of response to inhaled bronchodilators in asthmatics. Am Rev Respir Dis 1993, 127:680-685.

16. Newton MF, O'Donnell DE, Forkert L: Response of lung volumes to inhaled salbutamol in a large population of patients with severe hyperinflation. Chest 2002, 121:1042-1050.

17. O'Donnell DE, Forkert L, Webb KA: Evaluation of bronchodilator responses in patient with “irreversible" emphysema. Eur Respir J 2001, 18:914-920.

18. Newton MF, O'Donnell DE, Forkert L: Response of lung volumes to inhaled salbutamol in a large population of patients with severe hyperinflation. Chest 2002, 121:1042-1050.

19. Teeter JG, Bleecker ER: Relationship between airway obstruction and respiratory symptoms in adult asthmatics. Chest 1998, 11:272-277. 